\title{
STRATEGY OF MARKET SEGMENTATION, TARGETING AND POSITIONING IN INCREASING THE NUMBER OF CUSTOMERS AT PT. BANK MUAMALAT INDONESIA TbK KCP PANYABUNGAN
}

\author{
Rosdiyah $^{1}$, Abdul Nasser Hasibuan ${ }^{2}$, Azwar Hamid $^{3}$, Zulaika Matondang ${ }^{4}$ \\ ${ }^{1}$ IAIN Padangsidimpuan (Perbankan Syariah, FEBI, IAIN Padangsidimpuan) \\ ${ }^{2}$ IAIN Padangsidimpuan (Perbankan Syariah, FEBI, IAIN Padangsidimpuan) \\ ${ }^{3}$ IAIN Padangsidimpuan (Perbankan Syariah, FEBI, IAIN Padangsidimpuan) \\ ${ }^{4}$ IAIN Padangsidimpuan (Ekonomi Syariah, FEBI, IAIN Padangsidimpuan) \\ rosdiyah@gmail.com ${ }^{1}$, hasibuanabdulnasser@iain-padangsidimpuan.ac.id ${ }^{2}$, azwarhamid@iain- \\ padangsidimpuan.ac.id ${ }^{3}$ zulaikamatondang@iain-padangsidimpuan.ac.id $^{4}$
}

\begin{abstract}
ABSTRAK
Penelitian ini dilatarbelakangi oleh banyaknya masyarakat kota Panyabungan yang dominan beragama Islam yang akan memberikan keuntungan bagi bank syariah. Pemilihan pasar yang tepat dengan menggunkan strategi segmentasi pasar, targeting dan positioning yang akan membantu PT. Bank Muamalat Indonesia Tbk KCP Panyabungan dalam memilih nasabah potensi yang berguna untuk memenangkan persaingan dengan bank lainya. Metodologi penelitian yang digunakan adalah deskriptif kualitatif dengan menggunakan data primer dan data sekunder. Data primer diperoleh dengan teknik pengambilan data melalui wawancara dan observasi, sedangkan data sekundernya dari dokumen-dokumen BMI KCP Panyabungan. Hasil penelitian menemukan, strategi pemasaran produk-produk BMI KCP Panyabungan adalah segmentasi pasar dengan memilih segmentasi demografis dan prilaku. Kemudian targeting yaitu BMI KCP Panyabungan memilih pedagang, pengusaha dan pegawai sebagai target pasar. Selanjutnya positioning, BMI KCP Panyabungan membangun citra baik dengan merangkul para Ulama dan mengedukasi masyarakat bahwa PT. Bank Muamalat Indonesia merupakan bank Islami dan bebas dari riba serta, memberikan souvenir mengandung simbol kepada Ulama. Sedangkan kendala yang dihadapi ialah luas wilayah, pesaing lain.
\end{abstract}

Kata Kunci: Strategi, Segmentasi Pasar, Targeting, positioning

\begin{abstract}
This research is motivated by the large number of people in the city of Panyabungan who are predominantly Muslim who will provide benefits for Islamic banks. Selection of the right market by using market segmentation strategies, targeting and positioning that will help PT. Bank Muamalat Indonesia Tbk KCP Panyabungan in selecting potential customers who are useful to win competition with other banks. The research methodology used is descriptive qualitative using primary data and secondary data. Primary data were obtained by collecting data through interviews and observations, while secondary data were obtained from documents of BMI KCP Panyabungan. The research found that the marketing strategy for BMI KCP Panyabungan products was market segmentation by selecting demographic and behavioral segmentation. Then the targeting is that BMI KCP Panyabungan chooses traders, entrepreneurs and employees as the target market. Next to positioning, BMI KCP Panyabungan builds a good image by embracing Ulama and educating the public that PT.
\end{abstract}


Bank Muamalat Indonesia is an Islamic bank and is free from usury and provides souvenirs containing symbols to Ulama. Meanwhile, the obstacles faced are the size of the area, other competitors.

Keywords: Strategy, Market Segmentation, Targeting, Positioning

\section{A. PENDAHULUAN}

Perkembangan perbankan syariah di Indonesia telah menjadi tolak ukur keberhasilan eksistensi ekonomi syariah. Bank Muamalat Indonesia sebagai bank syariah pertama di Indonesia. keberhasil melewati krisis yang terjadi pada tahun 1998 serta menunjukkan kinerja yang semakin meningkat dan tidak menerima sepersen pun bantuan dari pemerintah dan pada krisis keuangan tahun 2008, dan bahkan Bank Muamalat Indonesia mampu memperoleh laba Rp. 300 miliar lebih pada saat itu. Hal tersebut menunjukkan bahwa perbankan syariah benar-benar tahan dan kebal krisis dan mampu tumbuh dengan signifikan. (Nofinawati:2015,67).

Lahirnya PT. Bank Muamalat Indonesia, Tbk juga merupakan awal bagi perkembangan perbankan syariah di Indonesia sehingga lahirlah bank- bank syariah lainnya. Seperti Bank Syariah Mandiri, BNI Syariah, BRI Syariah dan lainnya membuat tingkat persaingan semakin tinggi. Ditambah lagi dengan isu-isu kebangkuran PT. Bank Muamalat Indonesia, Tbk secara tidak langsung menyebabkan kurangnya kepercayaan masyarakat atas kinerja PT. Bank Muamalat Indonesia, sehingga PT. Bank Muamalat Indonesia, Tbk haruslah berusaha lebih keras lagi untuk mengembalikan kepercayaan masyarakat dengan cara menyusun strategi-strategi dalam mengupayakan untuk kemajuan dan keuntungan perusahaan.

Strategi pemasaran merupakan langkah awal suatu perusahaan dalam memperkenalkan produk pada konsumen. Hal tersebut sangat penting dilakukan untuk mendapatkan keuntungan yang diharapkan oleh perusahaan. Bagaimana Strategi pemasaran akan berjalan dengan optimal, kendati pun telah direncanakan secara terstruktur baik internal maupun eksternal. Dalam usaha menguasai pasar, strategi bersaing dapat dikembangkan dengan menyesuaikan berbagai kekuatan internal dan kekuatan eksternal perusahaan. Hal ini bertujuan agar perusahaan dapat merincikan secara mendalam setiap apa yang terjadi di lingkungan perusahaan. Penilaian yang secara objektif ini sangat penting untuk memperoleh competitive advantage dan memiliki produk yang sesuai dengan keinginan konsumen.(Jon Predianto Sihotang: 2017,2)

Dalam melakukan pemasaran, bank memiliki beberapa sasaran yang hendak dicapai. Artinya, nilai penting pemasaran bank terletak dari tujuan yang ingin dicapai tersebut 
Rosdiyah ${ }^{1}$, Abdul Nasser Hasibuan ${ }^{2}$, Azwar Hamid ${ }^{3}$, Zulaika Matondang ${ }^{4}$

seperti dalam hal meningkatkan mutu pelayanan dan menyediakan ragam produk yang sesuai dengan keinginan dan kebutuhan nasabah. (Abdul Nasser Hasibuan: 2018, 51) Sudut pandang konsumen tentu menjadi barometer bagi setiap perusahaan khususnya disini PT. Bank Muamalat Indonesia, Tbk untuk meciptakan strategi bersaing.

Hal ini sudah menjadi tuntutan karena menyampaikan produk untuk sampai kepada konsumen adalah tujuan akhir. Berorientasi kepada konsumen menjadi konsep utama dalam pengembangan produk bahkan strategi bersaing.(Jon Predianto Sihotang: 2017,2) Produk yang baik dan sesuai dengan keinginan pasar harusnya dapat membantu PT. Bank Muamalat Indonesia, Tbk untuk menarik minat nasabahnya. Hal tersebut tentunya menjadi tugas bagi manajemen dan bagian pemasaran untuk menyusun strategi yang sesuai agar dapat diimpelmentasikan dalam kegiatan usahanya dan memberikan dampak positif bagi bank itu sendiri.

Produk berbasis syariah akan lebih mudah dipasarkan oleh PT. Bank Muamalat Indonesia Tbk KCP Panyabungan yang selanjutnya akan ditulis oleh peneliti dengan BMI KCP Panyabungan apabila menggunakan strategi yang tepat. Hal tersebut dikarenakan, secara geografis wilayah kota Panyabungan di dominasi oleh masyarakat yang mayoritas beragama Islam.

Sehubungan dengan itu BMI KCP Panyabungan dapat memanfaatkan hal
POINT Vol. 1, No. 2, Des 2020 tersebut untuk memilih pasar yang tepat guna mengembangkan bisnisnya dan menarik masyarakat untuk menjadi nasabah penabung pada BMI KCP Panyabungan yang merupakan salah satu bank syariah di kota panyabungan. Namun keuntungan tersebut tentunya tidak hanya dimanfaatkan oleh BMI KCP Panyabungan saja. Hal tersebut dikarenakan di kota Panyabungan juga terdapat bank-bank syariah lainnya seperti Bank Mandiri Syariah dan Bank Sumut Syariah yang memiliki keunggulan dan kelebihannya masing-masing. Hal tersebut tentunya juga menjadi perhati an bagi BMI KCP Panyabungan dalam memilih strategi bersaing yang tepat.

\section{B. METODE}

Penelitian dilakukan di PT. Bank Muamalat Indonesia Tbk KCP Panyabungan dengan menggunakan metode penelitian kualitatif deskriptif, subjek penelitian karyawan dan nasabah PT. Bank Muamalat Indonesia Tbk KCP Panyabungan yang bersangkutan dengan penelitian ini dengan menggunakan sumber data primer dan data sekunder, metode pengumpulan data yaitu: opservasi, wawancara terstruktur dengan menggunakan pedoman wawancara, dan dokumentasi. Metode pengecekan keabsahan data yaitu triangulasi sumber, metode analisis data yaitu reduksi data, penyajian data dan penarikan kesimpulan. 


\section{HASIL DAN PEMBAHASAN}

1. Strategi Segmentasi Pasar pada PT. Bank Muamalat Indonesia Tbk KCP Panyabungan.

BMI KCP Panyabungan merupakan lembaga keuangan syariah yang melakukan kegiatan menghimpun dana dari masyarakat yang memiliki kelebihan dana. Dalam upaya mencari pangsa pasar atau nasabah BMI KCP Panyabungan menggunakan strategi pemasaran dan juga strategi bersaing untuk menarik nasabah dan dalam waktu yang bersamaan juga untuk memenangkan persaingan. BMI KCP Panyabungan mencoba untuk bergabung secara langsung kepada masyarakat dan mengidentifikasi karakter dari nasabah maupun calon nasabah untuk melakukan penyesuaian produk $\mathrm{BMI} \mathrm{KCP}$ Panyabungan yang nantinya akan ditawarkan. Dimana langkah pertama yang dilakukan BMI KCP Panyabungan yaitu melakukan segmentasi pasar. Dari hasil penelitian yang peneliti lakukan di BMI KCP Panyabungan, Relationship Marketing Funding mengelompokkan pasarnya berdasarkan beberapa segmen:

a. Segmentasi geografis

Segmentasi geografis adalah Pengelompokan pasar yang didasarkan daerah seperti Negara, wilayah, propinsi, kota, atau lingkungan rumah tangga. Pada segmen ini BMI KCP Panyabungan tidak melakukan pemetaan wilayah untuk memasarkan produk-produknya. Dalam memasarkan produk-produknya $\quad \mathrm{BMI} \quad \mathrm{KCP}$ Panyabungan memberi kebebasan bagi petugas pemasarannya untuk mencari nasabah dan memasarkan produkproduknya sampai ke wilayah manapun. Namun petugas pemasaran memanfaatkan wilayah kota panyabungan yang di dominasi oleh masyarakat yang beragama islam untuk mensosialisasikan produknya yang berbasis syariah yaitu dengan sistem bagi hasil dan tidak mengandung riba.

b. Segmentasi demografis Segmentasi demografis merupakan dasar untuk membedakan berbagai macam kelompok berdasarkan variabel seperti usia, ukuran keluarga, siklus hidup keluarga, jenis kelamin, penghasilan, pekerjaan, pendidikan, agama, ras, generasi, kewarganegaraan, dan kelas sosial. Dari hasil penelitian yang peneliti lakukan di BMI KCP Panyabungan, dimana BMI KCP Panyabungan mengelompokkan pasarnya pada variabel pekerjaan dan pendidikan. pada variabel pekerjaan BMI KCP Panyabungan memilih segmen yang mempunyai pekerjaan sebagai pedagang pasar, pengusaha dan pegawai. BMI KCP Panyabungan dalam hal ini memilih pedagang pasar, pengusaha dan pegawai karena mereka 
Rosdiyah ${ }^{1}$, Abdul Nasser Hasibuan ${ }^{2}$, Azwar Hamid ${ }^{3}$, Zulaika Matondang ${ }^{4}$

sudah memiliki penghasilan. Selain itu pengusaha juga merupakan pasar yang potensial bagi BMI KCP Panyabungan.

Untuk variabel pendidikan BMI KCP Panyabungan lebih memilih siswa dan pelajar dari sekolah, yayasan dan lembaga pendidikan islam. Hal tersebut dikarenakan banyaknya sekolah atau lembaga pendidikan Islam seperti pesantren di Mandailing Natal. Siswa dan pelajar dari sekolah, yayasan dan lembaga pendidikan islam juga merupakan salah satu pasar yang potensial bagi BMI KCP Panyabungan.

c. Segmen perilaku

Segmentasi prilaku merupakan pengelompokan pasar atas dasar pengetahuan, sikap, tingkat penggunaan, manfaat, atau respon yang diberikan terhadap suatu produk. Berdasarkan hasil wawancara dengan dengan Ibu Hamidah selaku pegawai bagian pemasaran BMI KCP Panyabungan. Mereka memilih segmentasi perilaku pada variabel tingkat kegunaan dan manfaat. Dimana tingkat kegunaan dan manfaat dari suatu produk digunakan untuk menarik minat pasar sasaran yang mempunyai kebutuhan tertentu. Pemasaran sebuah produk akan diterima oleh masyarakat jika produk itu memang dibutuhkan. Maka dari itu strategi yang dilakukan BMI KCP Panyabungan yaitu
POINT Vol. 1, No. 2, Des 2020 menawarkan produk yang dapat menguntungkan dan memenuhi kebutuhan nasabah maupun calon nasabah seperti tabungan haji bagi nasabah yang ingin ibadah atau deposito bagi nasabah yang ingin keuntungan bagi hasil yang leih besar.

2. Strategi Targetting pada PT. Bank Muamalat Indonesia Tbk KCP Panyabungan.

Strategi targeting merupakan langkah lanjutan setelah segmentasi pasar. Maksudnya yaitu setelah kegiatan membagi-bagi pasar maka dipilihlah satu atau lebih dari pasar yang akan dilayani. Menetapkan pasar sasaran artinya mengevaluasi keaktifan setiap segmen, kemudian memilih salah satu dari segmen pasar atau lebih untuk dilayani. Pada tahap ini strategi yang dilakukan oleh tim pemasaran BMI KCP Panyabungan dalam menentukan target pasar adalah dengan melakukan pendekatan kepada calon nasabah untuk mengetahui seberapa potensial target pasar tersebut dengan cara mengidentifikasi karakteristik dari nasabah maupun calon nasabah.

Dalam hal ini, pasar sasaran yang dituju oleh tim pemasaran adalah calon nasabah yang membutuhkan jasa pengelolaan keuangan melalui produk simpanan seperti pedagang, pengusaha, pegawai dan orang-orang yang memiliki kelebihan dana lainnya. Dalam 
memasarkan produk, BMI KCP Panyabungan menyasar satu atau lebih segmen yang memiliki nilai tinggi bagi perusahaan melalui:(Kasmir:2010,104)

a. Pemasaran serba sama, melayani semua pasar dan tawarkan pasar dalam arti tidak ada perbedaan. Mencari apa yang sama dalam kebutuhan konsumen. Biasanya untuk produk massal seperti tabungan dengan akad wadiah untuk semua lapisan masyarakat mulai dari kelangan bawah, menengah dan kalang atas.

b. Pemasaran serba aneka, merancang tawaran untuk semua pendapatan, tujuan dan kepribadian. Seperti produk simpanan yang memberikan keuntungan bagi calon nasabah. Contohnya deposito, giro, tabungan haji dan lain sebagainya.

3. Strategi Positioning pada PT. Bank Muamalat Indonesia Tbk KCP Panyabungan.

Positioning merupakan hal yang penting dilakukan guna memaksimalkan strategi segmentasi pasar yang telah dilakukan oleh petugas pemasaran. Positioning adalah tindakan perusahaan untuk merancang produk dan bauran pesaran agar dapat tercipta tertentu diingatan konsumen, sehingga dengan demikian konsumen segmen memahami dan menghargai apa yang dilaksanakan
perusahaan.(M. Manulang \& Esterlina Hutabarat:2016,74) BMI KCP Panyabungan memposisikan dirinya sebagai lembaga keuangan yang menghimpun dana dari masyarakat melalui produk penghimpun dana. Produk penghimpunan dana akan diterima jika calon nasabah benar-benar meyakini produk tersebut akan menguntungkannya.

Maka positioning digunakan sebagai strategi dalam menempatkan produk kepada nasabah yang benar-benar membutuhkan produk tersebut. sedangkan Tujuan dari positioning itu sendiri adalah sebagai upaya menempatkan produk yang ada pada pelanggan agar mendapat tempat yang lebih unggul dibandingkan dengan produk-produk pesaing. BMI KCP Panyabungan melakukan positioning dengan cara:

a. Mengenali keunggulan-keunggulan produk yang mungkin dapat menampilkan perbedaan antara produk PT. Bank Muamalat Indonesia, Tbk dengan produk pesaing. Dalam menempatkan posisi produk atas pasar maka BMI KCP Panyabungan mengenali terlebih dahulu keunggulan kompetitif yang akan memberikan nilai tambah pada produk mereka. Seperti produk tabungan yang berbasis syariah dengan cara bagi hasil bukan bunga. 
Rosdiyah ${ }^{1}$, Abdul Nasser Hasibuan ${ }^{2}$, Azwar Hamid ${ }^{3}$, Zulaika Matondang ${ }^{4}$

b. Menyampaikan keunggulan secara efektif kepada target pasar. Dalam memasarkan produknya tim pemasaran BMI KCP Panyabungan menyampaikan produk dengan baik dan sesuai dengan keadaan yang ada pada produk tersebut. Melalui komunikasi yang berisi pesan, tim pemasaran dapat meningkatkan kepercayaan dari nasabah maupun calon nasabah. Contohnya dalam menyampaikan kelebihan produk, BMI KCP Panyabungan lebih menekankan prinsip-prinsip syariahnya dan juga menjelaskan mengenai hukum riba.

Keantusiasan masyarakat Kabupaten Mandailing Natal untuk menggunakan bank syariah memberikan kemudahan BMI KCP Panyabungan dalam memperkenalkan produk-produnya yang berbasis syariah. Salah satu cara BMI KCP Panyabungan dalam memperkenalkan produknya agar lebih dikenal di masyarakat dengan melakukan kunjungan ke pesantrenpesantren seperti Musthafawiyah dan merangkul para Tokoh Agama atau Ulama. Hal ini dilakukan karena Ulama dapat menyampaikan kepada masyarakat tentang larangan riba dan supaya masyarakat mau menggunakan jasa bank syariah. BMI KCP Panyabungan melalui tim pemasarannya juga melakukan kunjungan ke pesta pernikahan yang di adakan oleh nasabah untuk menimbulkan kesan baik
POINT Vol. 1, No. 2, Des 2020 serta meningkatkan rasa kepercayaan dan loyalitas nasabah Bank Muamalat.

Positioning merupakan strategi terakhir dari strategi STP. Untuk mengetahui keefektifan dari strategi ini. Peneliti mengumpulkan Informasi dari nasabah dengan melakukan wawancara sebagai berikut. Berdasarkan wawancara dengan ibu Rahmayani, ibu Lina dan bapak Muhammad llyas menyatakan bahwa:

“Mereka mengenal PT. Bank Muamalat Indonesia Tbk melalui kerja sama antara BMI KCP Panyabungan dengan yayasan, pesantren, dan sekolah tempat mereka bekerja. Keunggulan dari BMI KCP Panyabungan terletak pada pelayanannya. Serta citra PT. Bank Muamlat Indonesia Tbk yang memakai prinsip syariah dan terhindar dari riba menarik minat mereka untuk menabung di BMI KCP Panyabungan ."

Dari kesimpulan wawancara sebelumnya strategi yang dilakukan BMI KCP Panyabungan diketahui bahwa penerapkan strategi STP dalam memasarkan produk juga memberikan citra baik bagi PT. Bank Muamalat Indonesia, Tbk baik itu dinilai dari segi pelayanannya maupun dari prinsip syariahnya. Kemudian penjelasan selanjutnya ditambahi kembali oleh ibu 
Alimah, ibu Rahmayani, dan ibu lina yang menyatakan bahwa:

Kesan yang dirasakan mereka menjadi nasabah Bank Muamalat yaitu baik, puas, dan bebas riba.

Jadi positioning yang dilakukan BMI KCP Panyabungan dalam hal ini adalah menempatkan posisi produk agar mendapat posisi tersendiri di benak nasabah bisa dikatakan cukup baik. Hal tersebut dapat kita ketahui dari respon nasabah yang telah di wawancara.

BMI KCP Panyabungan menggunakan segmentasi pasar untuk merancang strategi bersaing. Karena karakteristik nasabah yang terlalu beragam, BMI KCP Panyabungan membagi pasarnya berdasarkan pada segmentasi demografis dan segmentasi prilaku, dimana untuk segmentasi demografis BMI KCP Panyabungan membagi pasarnya berdasarkan variabel pekerjaan dan pendidikan.

Dari variabel pekerjaan BMI KCP Panyabungan memilih nasabah yang memiliki pekerjaan sebagai pedagang pasar, pengusaha dan PNS yang sudah pasti memiliki penghasilan. Sedangkan dari variabel pendidikan BMI KCP Panyabungan memilih pelajar atau siswa dari yayasan atau lembaga pendidikan islam seperti SDIT atau pondok pesantren yang ada di Mandailing Natal. Banyaknya sekolah atau lembaga pendidikan Islam di Mandailing Natal menyebabkan BMI KCP Panyabungan memilih pelajar menjadi pasar yang potensial bagi BMI
KCP Panyabungan. Salah satu contohnya ialah pondok pesantren Mustafawiyah yang memiliki 7000 santri.

Selanjutnya ialah segmentasi perilaku, BMI KCP Panyabungan mengelompokan pasarnya berdasarkan variabel tingkat kegunaan atau manfaat dari suatu barang. BMI KCP Panyabungan memilih nasabah maupun calon nasabah yang memiliki kebutuhan tertentu. Contohnya kepentingan ibadah, BMI KCP Panyabungan menawarkan produk tabungan haji kepada nasabah yang membutuhkan jasa keuangan untuk mempermudah nasabah dalam pelaksanaan haji.

Selanjutnya strategi targeting yang diterapkan BMI KCP Panyabungan berupa evaluasi langsung dengan melakukan pendekatan kepada nasabah maupun calon nasabah yang diperkirakan potensial bagi BMI KCP Panyabungan. Selain untuk mengetahui seberapa potensial target pasat tersebut, targeting juga berguna untuk menyeleksi pasar yang memiliki kriteria-kriteria tertentu. Sehingga BMI KCP Panyabungan dapat menentukan strategi pemasaran yang cocok untuk target sasaran tersebut. Dari evaluasi segmen-segmen pasar, BMI KCP Panyabungan memilih Pengusaha dan pegawai yang membutuhkan bantuan dalam pengelolaan dana.

Sedangkan Strategi positioning berguna sebagai upaya menempatkan produk agar mendapat nilai lebih dimata nasabah maupun 
Rosdiyah ${ }^{1}$, Abdul Nasser Hasibuan ${ }^{2}$, Azwar Hamid ${ }^{3}$, Zulaika Matondang ${ }^{4}$

calon nasabah. BMI KCP Panyabungan menanamkan pada nasabah maupun calon nasabahnya bahwa PT. Bank Muamalat Indonesia, Tbk merupakan bank islami yang berlandasakan syariah dan bebas dari riba. Dengan mendatangi majenis-majelis dan memberikan edukasi BMI KCP Panyabungan berupaya memberikan pemahaman bagi masyarakat tentang bahaya riba.

Selain itu BMI KCP Panyabungan juga melakukan kunjungan kepesantren-pesantren dan merangkul para Ulama dikarenakan para ulama dapat memberikan wawasannya kepada masyarakat mengenai hukum riba menurut Islam. Bukan hanya itu, kegiatan tersebut juga berguna untuk membangun citra baik BMI KCP Panyabungan dimata masyarakat Mandailing Natal.

Melalui para Ulama, BMI KCP Panyabungan juga memcoba menarik perhatian dan meyakinkan masyarakat dengan cara memberikan souvenir-souvenir yang memiliki simbol PT. Bank Muamalat Indonesia. Souvenir yang berupa cindra mata seperti payung, jam dan lainnya merupakan strategi yang digunakan BMI KCP Panyabungan untuk mengubah persepsi masyarakat. Dengan begitu masyarakat akan berpikir bahwa para Ulama memilih BMI KCP Panyabungan sebagai bank islam yang dapat dipercaya dan harapannya masyarakat juga akan mencontoh apa yang dilakukan oleh para Ulama tersebut.

\section{PENUTUP}

\section{Kesimpulan}

Berdasarkan hasil penelitian dan pembahasan pengaruh pengetahuan terhadap minat memilih produk PT. Bank Syariah Mandiri Padangsidimpuan (studi kasus pada guru alazhar bi'ibadillah ujung gading kecamatan batang angkola) dengan melalui penyebaran angket/kuesioner kepada guru Al-Azhar Bi'ibadillah, maka dapat diambil kesimpulan bahwa pengetahuan berpengaruh dan signifikan terhadap minat memilih produk PT Bank Syariah Mandiri Padangsidimpuan.

Hipotesis yang menyatakan pengetahuan berpengaruh terhadap minat memilih produk PT Bank Syariah Mandiri Padangsidimpuan dapat diterima. Presentase sumbangan pengetahuan terhadap minat memilih produk PT Bank Syariah Mandiri Padangsidimpuan sebesar $12 \%$ dan selebihnya $88 \%$ dipengaruhi oleh variabel independen lain yang tidak dibahas dalam penelitian ini.

\section{Saran}

Semoga adanya strategi yang menarik minat nasabah dalam perbankan syariah.

\section{DAFTAR PUSTAKA}

Andi Prastowo, Memahami Metode-metode Penelitian: Suatu Tinjauan Teoritis dan Praktis Jogjakarta: Ar-Ruzz Media, 2014.

Adrianto, Manajemen Bank Syariah Implementasi Teori dan Praktek CV. Penerbit Qiara Media, 2019. 
Abdul Rahman Saleh dan Muhbib Abdul Wahab, Psikologi Suatu Pengantar dalam Perspektif Islam Jakarta: Penada Media, 2004.

Amsal Bakhtiar, Filsafat Ilmu Jakarta: PT.Raja Grafindo Persada, 2010.

Arikunto S, Evaluasi Pendidikan Jakarta: Rineka Cipta, 1994.

Ahmad Tafsir, Filsafat Umum Akal dan Hati Sejak Thales Sampai Capra Bandung: PT Remaja Rosdakarya, 2003.

Choirul Mahfud, Pendidikan Multikultural Yogyakarta: Pustaka Pelajar, 2013.

Departemen Pendidikan Nasional, Kamus Besar Indonesia Jakarta: Balai Pustaka, 2005.

Dedy Mulyana, Metode Penelitian Kualitatif Yogyakarta: Pustaka Pelajar, 2006.
Ismail, Perbankan Syariah Jakarta: Prenadamedia Group, 2014.

Kasmir, Manajemen Perbankan Jakarta: Rajawali Pers, 2012.

Muhammad Uzer Usman, Menjadi Guru Profesional Bandung: PT. Remaja Rosdakarya, 2003 cet, ke-25.

Muhammad, Metodologi Penelitian Ekonomi Islam Jakarta: Raja Wali Press, 2009.

Mudrajad Kuncoro, Metode Riset Bisnis dan Ekonomi Jakarta: PT. Raja Grafindo Persada, 2010.

Mardalis, Metode Penelitian Suatu Pendekatan Proposal Jakarta: Bumi Aksara, 2007. 